\title{
The next phase of healthcare improvement: what can we learn from social movements?
}

\author{
P Bate, G Robert, H Bevan
}

Qual Saf Health Care 2004;13:62-66. doi: 10.1136/qshc.2003.006965

To date, improvement in health care has relied mainly on a "top down" programme by programme approach to service change and development. This has spawned a multitude of different and often impressive improvement schemes and activities. We question whether what has been happening will be sufficient to achieve the desired scale of change within the time scales set. Is it a case of "more of the same" or are there new and different approaches that might now be usefully implemented? Evidence from the social sciences suggests that other perspectives may help to recast large scale organisational change efforts in a new light and offer a different, though complementary, approach to improvement thinking and practice. Particularly prominent is the recognition that such large scale change in organisations relies not only on the "external drivers" but on the ability to connect with and mobilise people's own "internal" energies and drivers for change, thus creating a "bottom up" locally led "grass roots" movement for improvement and change.

See end of article for authors' affiliations

Correspondence to: Professor P Bate, Chair of Health Services

Management, CHIME, Royal Free and University College Medical School, University College London, The Archway Campus, London N19 3UA, UK; s.p.bate@chime.ucl.ac.uk
$\mathrm{H}$ ealthcare systems around the world are engaged in striving to make radical and sustainable changes through various programmatic approaches to improvement. For instance, in the UK the NHS Plan was published in July 2000 promising "a revolution in health care" over the next 10 years. "Radical action" through increased investment and reform would put "patients and people at the heart of the NHS". ${ }^{1}$ The words and language of this and other similar international programmes leave no doubt that what is being envisaged is big, bold, transformational change.

The Institute of Medicine in its seminal 2001 report, Crossing the Quality Chasm: A New Health System for the 21st Century describes the "chasm" between the unacceptably poor standards of current care delivery systems and what it could and should be in the context of the USA. It provides a challenging manifesto for transformation of the American healthcare system as a whole. $^{2}$

The Australian Council for Safety and Quality in Health Care has set out a radical platform for investment in health systems redesign, system capacity building, cultural development, and enabling patients to be partners in their own care. ${ }^{3}$
Internationally there is a parallel realisation and understanding that the design of the existing healthcare system will not deliver what is required for the future. All these plans and publications set out bold aims and targets. However, none of them specify how the leverage that will deliver the changes will be created.

\section{A MOVEMENT FOR HEALTHCARE IMPROVEMENT}

Most ideas that underpin contemporary healthcare improvement initiatives are derived from planned or "programmatic" approaches to change. ${ }^{4}$ These approaches are most frequently described in the literature on organisational and management studies which encompasses organisational development, strategy and design, and individual and team development (as well as increasingly significant research that focuses upon sensemaking ${ }^{5}{ }^{6}$ ). However, there is another so far unused research base in the social and political sciences that offers an entirely different perspective on how large scale change occurs. This is social movements theory ${ }^{7-9}$ which seeks to explain "why collective episodes [such as movements and protest] occur where they do, when they do, and in the ways they do?". ${ }^{10}$

As part of a wider initiative led by the NHS Modernisation Agency (box 1) to encourage closer links between theory and practice, a number of leading improvement practitioners, healthcare managers, clinicians, and policy makers in the UK met in July 2002 to debate and challenge the dominant ideas in this field of research (box 2).

In particular, the group considered what implications other theories of large systems improvement may have for the way healthcare modernisation and reform might be approached in the future, thereby enacting the notion of transferring research into practice. During the colloquium the group explored the potential of social movements theory as distinct from the usual "programmatic" approach and, in particular, considered its applicability to the conceptand feasibility of creating-a healthcare improvement movement.

The colloquium attempted to draw out some of the contrasts between the programmatic and social movement perspectives on change that are pertinent within the context of approaches to healthcare improvement and modernisation (table 1).

These two perspectives are based on very different underpinning assumptions about change which have important implications for NHS policymakers. For instance, with regard to 


\section{Box 1 The NHS Modernisation Agency}

- The role of the NHS Modernisation Agency is to support the NHS in making radical and sustainable changes to services for the benefit of patients, as part of what has been called "the largest concerted systematic improvement effort ever undertaken, anywhere, in any industry" (Don Berwick, Institute for Healthcare Improvement, US).

- The Agency has a core staff of 200 and runs over 50 projects and programmes aimed at modernising services. The approach to modernisation in the UK has evolved as follows:

- 1998: The first national NHS modernisation programme began; disparate national pilot projects were initiated but with little support on the "how"; local work was going on in isolation.

- 1998 onwards: First national pilot projects that focused both on "what" to change and the "how" of change; start of national targets and the NHS Plan.

- From 2000 onwards: Proliferation of national programmes; formation of NHS Modernisation Agency (2001); move from national to local as many more local teams started to take up this work; but how to move from a few national pilot projects to countrywide?

- 2003: Over 3000 local teams; encouraging results but need to accelerate rate and spread of change.

- In addition to these modernisation programmeswhich employ a range of quality improvement and service redesign tools and techniques-the Agency provides leadership and management development courses across a wide range of NHS staff groups.

social movements, there is no pressure to obtain "buy in" to persuade or to produce a compelling case for change since people have already independently accepted and embraced the need for change: they have inwardly made the case for and to themselves. It has become not an option but an imperative, and by doing so strengthens commitment to overcome any difficulties. ${ }^{14}$ Another difference is that it is no longer appropriate to talk about "overcoming resistance to change" since, from a social movements perspective, resistance is necessary for change to happen. The resistance itself points to the need for something new, and it energises people to work towards movement ends; only in the face of opposition has significant social change been achieved. ${ }^{16}$ The biggest difference between the two perspectives is that, while the programmatic approach focuses on plans, the movements approach focuses on energy with words like "epidemic", "contagion", and "explosion" used to describe the power and spread of that energy. These notions are similar to the concepts outlined by Gladwell in his book The Tipping Point which examines "the social epidemics that surround us" and aims to show people how to start "positive" epidemics of their own. ${ }^{17}$

\section{THE SOCIAL MOVEMENTS PERSPECTIVE}

Although the objection to the application of a social movements perspective is usually that social change is different from organisational change, there are in fact strong similarities in terms of the mechanisms by which organisations and social movements (such as environmental or peace movements) develop and change. ${ }^{14}$ Indeed, the presence of formal and informal organisation might positively assist
Box 2 "What can the NHS learn from social movements?" Colloquium, July 2002

Aims

- To explore NHS modernisation and improvement from the alternative perspective of social movements and identify the implications of this perspective for the way we go about modernisation.

- To understand how a movement works and unfoldsdynamics, stages, preconditions and essential elements.

- To consider how we might begin to engender a "movement mentality" or movement sensibilities around NHS modernisation.

\section{Method}

The approach adopted was that of a "joint interpretive forum"111 which brought together members of different stakeholder groups to jointly reflect upon and interpret academic research ${ }^{12}$ and to examine its significance in terms of action ${ }^{13}$ as part of an ongoing process of collective sensemaking. A discussion paper and questionnaire were pre-circulated. After an introductory presentation and feedback on the questionnaire responses, group discussion was facilitated by the authors (PB, HB and GR). A polarity management exercise was also undertaken. ${ }^{15}$ The proceedings were tape recorded and transcribed.

\section{Attendees}

Fiffeen individuals were invited to provide a cross section of people closely involved with planning and implementing NHS modernisation. The group included staff drawn from across the NHS Modernisation Agency, the Institute for Healthcare Improvement, policy makers, a hospital trust chief executive, and clinicians who had been closely involved with one or more modernisation programmes.

movement formation. The social movement framework may therefore be useful for understanding large scale mobilisation efforts inside healthcare systems.

Social movement and organisation theorists alike have recognised that change is usually gradual and evolutionary, often running out of steam before reaching its final destination. This is also why, in recent years, a number of private sector organisations have themselves turned away from traditional organisational development and formal programmes of change to more informal "communities of

Table 1 "Programmatic" and social movements perspectives on change

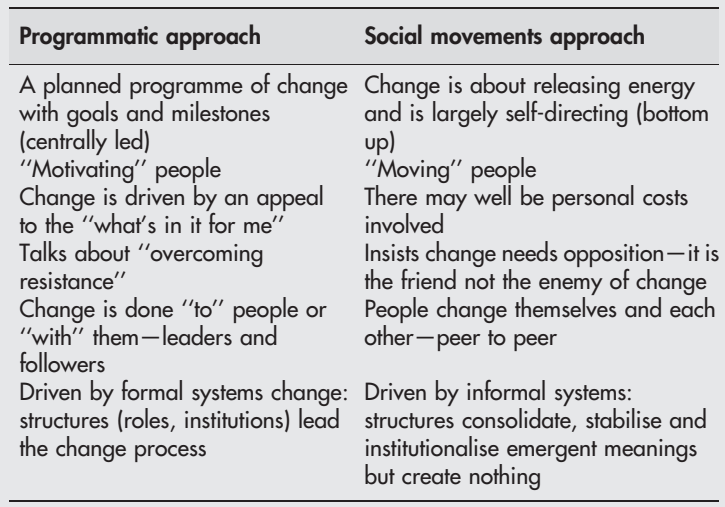


practice" based approaches, ${ }^{18}$ not that dissimilar from social movements thinking. The common emphasis of these approaches is on self-managed change which is much more unplanned and spontaneous and which finds its energy from the commitments of those involved both to the ends they are collectively seeking to achieve and to each other- "adherence to the spirit of the change goals rather than just to the letter". ${ }^{19}$

Broadly, the purist social movements perspective would advocate that healthcare improvement strategies need to extend beyond the present centre led programme by programme approach to embrace a concept of citizen led (healthcare staff and/or user) change that draws upon unstructured and largely self-organising autocatalytic (selffuelling) phenomena. Such factors characterise social movements where "elites" seek to set mobilisation processes in motion (and then help coordinate and resource them) rather than establish yet another new programme. This is why we find the phrase "orchestrated social movement" in the literature when referring to organisational movements, suggesting that change is not managed as such but liberated, channelled, and enabled. Questions raised at the colloquium therefore included:

- What are the characteristics of successful large scale mobilising efforts?

- Why do people join movements and why do they become activists?

- Why would people join a healthcare improvement movement as they might any other movement?

- Are those staff currently involved in improvement activities the most important people for delivering radical changes in the quality of health care provided on the ground?

\section{THE NEXT PHASE OF HEALTHCARE IMPROVEMENT}

Overall, attendees at the colloquium concluded that those leading and implementing modernisation in the NHS may benefit from considering the change task from the alternative perspective of social movements, as distinct from the usual organisation studies and change management perspective. Figure 1 presents a three stage model of building such a movement which arose from the colloquium.

A key challenge arising from applying this model in a health care context is how, firstly, to leverage the existing latent potential for change within a specific healthcare system and, secondly, to secure wider and deeper participation in a movement for improvement. In other words, how to enable healthcare staff to enrol voluntarily or sign up and participate actively in improvement activities.

The social movements perspective (table l) suggests that the more one person's meanings, values, aspirations, identity,

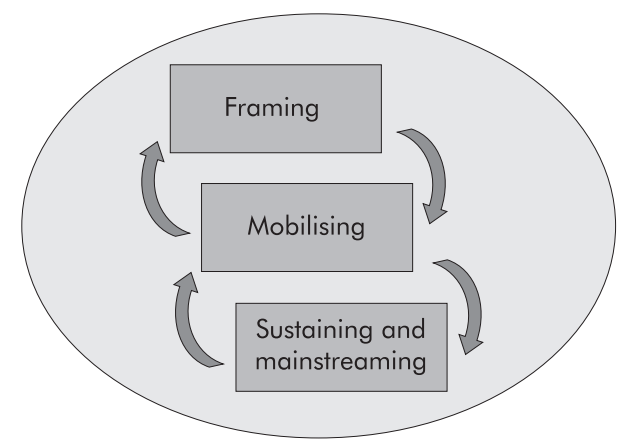

Figure 1 Three stages to build a movement. and personal biography align with those of the movement (the individual's receptivity to change), the more likely that person is to join and invest significant emotional energy. This is not just a matter of chance or coincidence. Alignment is very much a matter of how the case or cause is "framed" and presented by the leaders-that is, the actual words and language that make up the "script" for improvement will be decisive in capturing people's attention and intention. This begs the question as to whether existing scripts are the right ones or whether there are better "mobilising frames" and narratives for fostering solidarity. This question resonated with attendees at the colloquium-for example, existing improvement programmes in the NHS (such as the Cancer Services Collaborative ${ }^{20}$ ) with their explicit focus on improving patient outcomes and experiences and the close involvement of clinicians in objective setting were proving more successful in terms of engaging clinicians than programmes focusing solely on improving access to services (such as the booked admissions programme ${ }^{21}$ ). Social movements theory would suggest that the latter are less congruent with the "frames" of the clinical community. Securing this initial involvement is the crucial issue since, once individuals have joined, the interactions and relationships they build tend to ensure that they stay with the movement. Thus, from this perspective, sustainability and mainstreaming is very much a social issue-a question of collective identity, commitment, and purpose.

The core issue in social movements theory is "local mobilisation" or grass roots change. At the individual level, mobilisation refers to the concrete actions taken by a person in the direction of change while, at the organisational level, mobilisation refers to the process of rallying and propelling segments of the organisation to undertake joint action and to realise common change goals. ${ }^{19}$

Social movements theory postulates that changes are only likely to "catch hold" on the ground-or even be recognised as viable possibilities in the first place-if they are consistent with local customs, habits, aspirations, and passions. Participating in a movement does not appeal to, nor find its forward movement from, reason but from emotion-from seeing participation as an opportunity or a challenge. For a movement to form, people must be "moved"22; Snow et al talk about the mobilisation of "sentiment pools"-people's inner feelings ${ }^{23}$ which can help to overcome uncertainty and difficulties.

This in turn raises the question of whether a publicly funded healthcare system such as the NHS is too big (and diverse) for a single movement. We know that most movements begin in localities (geographical and professional) and, if successful, may ultimately run into and join up with each other: "a merger or coalition of existing groups rather than an organisational offshoot of a single group". ${ }^{24}$ A typical hospital system or community in the NHS will currently host up to 50 separate improvement initiatives: how can they be joined up so that the sum may become greater than the parts? From this social movements perspective the NHS Modernisation Agency's shifting emphasis away from national policies aimed at shaping local policy agendas and towards creating capacity for modernisation and improvement locally is a direction which fits well with what a social movements perspective would prescribe. Movements need local "activists" and "flag bearers" who will "convert" their peers and so form the critical mass of support for sustained change and improvement, and again the Agency's "Modernisation Associates" initiative at the hospital level is highly consistent with social movements thinking.

Some words of caution are needed. Firstly, some commentators remind us that "the outcomes of most movements are modest", that most "operate on the margins of success with 


\section{Key messages}

- To date, healthcare improvement and modernisation has mainly relied upon the classic planned incremental "programmatic" approach to service change and development.

- The results from these approaches are encouraging. However, in the UK, for example, it is estimated that fewer than $15 \%$ of NHS staff participate in these formal improvement activities. We ask whether current programmatic approaches are sufficient to achieve the scale of change required in the shortest possible time.

- Evidence from the social sciences suggests that a social movements perspective may help to recast large scale "transformative" organisational change efforts in a new light by offering a different, but complementary, approach to current healthcare improvement thinking and practice.

burnout a common companion to mobilisation" ${ }^{8}$ In short, just as with organisational change programmes, we tend to hear more about successful movements than unsuccessful ones. Secondly, whereas organisations consist of instrumental organised behaviour, social movements are spontaneous, unpredictable, unorganised, and unstructured phenomena driven more by emotion than reason. ${ }^{25}$ Many argue that movements cannot therefore be engineered, directed, or controlled and counsel against the futility of "planning" a movement. ${ }^{26}$ Clearly, the "centre" cannot intervene directly to create a movement; what it has to do instead is to focus on identifying and creating the receptive context (organisational, structural, political, cultural) and triggering conditions that will bring the movement into life. Finally, we need to flag up some of the ethical and moral issues that lurk in the movements concept: they can be forces for good as much as they can be forces for ill-the challenge is to understand what makes the one (passion) and the other (manipulation).

Little work has been done to combine or share learning from the two very different perspectives on change offered by traditional programmatic approaches and social movement theories. Yet there is a need to be constantly mindful of and to constantly critique the current "taken for granted" approach to improvement and modernisation in health care-not that it is necessarily "wrong" but that it is currently the only approach that is being considered. Because the social movements perspective is so different from mainstream thinking, it may help NHS leaders to consider how they might begin to engender a "movement mentality" or movement sensibilities around healthcare improvement and what might be done to facilitate its development.

Following the colloquium, further work in the UK is continuing to identify the implications of this new perspective for the way modernisation is done at both the local and national level. This research is focusing on the local level; how NHS staff in their trusts (whether members of modernisation teams or clinical departments) make sense of their role and behaviours within their professional groupings, wider healthcare community, and networks. In this way we will be put in touch with a wider group of leaders and "activists" so we will be able to obtain their views on, and assess the impact over time of, the existing and the new approaches to modernisation and service improvement. We want to try to understand the mind of the "activist" and the effectiveness of the various methods and strategies they employ; we want to know what they do with the emerging ideas as an approach to change, what kinds of obstacles they encounter and how they seek to get around them; and we want to share this stream of data with them so that they can reflect upon and develop their strategic scripts and routines. Only by ensuring that messages about modernisation and service improvement resonate with such existing "realities" can the chances of securing meaningful change in behaviour be maximised.

\section{CONCLUSION}

Attempting to implement a social movements type of approach in contemporary healthcare systems may have the potential for unintended and perhaps unwelcome consequences. However, this is no justification for not temporarily stepping back from the current widely accepted approaches to modernisation and questioning whether social movements thinking may offer "added value". Indeed, we would argue that the components of a social movements and a programmatic approach to large scale organisational change are not necessarily mutually exclusive and may represent the next phase of healthcare improvement.

\section{ACKNOWLEDGEMENTS}

We would like to thank the two reviewers and the editor for their helpful comments on an earlier draft of this paper. This work is supported by a grant from the NHS Modernisation Agency. The views expressed within it are those of the authors and not necessarily those of the sponsoring organisation.

\section{Authors' affiliations}

P Bate, G Robert, Centre for Health Informatics and Multiprofessional Education, University College London, London, UK

H Bevan, NHS Modernisation Agency, London, UK

\section{REFERENCES}

1 Department of Health. The NHS Plan: a plan for investment, a plan for reform. London: Department of Health, 2000.

2 Institute of Medicine. Crossing the quality chasm: a new health system for the 21 st century. Washington, DC: National Academy Press, 2001.

3 Australian Council for Safety and Quality in Health Care. Patient safety: towards sustainable improvement. Fourth report to the Australian Ministers' Conference, Sydney, 2003.

4 Pettigrew AM. Success and failure in corporate transformation initiatives. In: Galliers RD, Baets WRJ, eds. Information technology and organisational transformation. Chichester: Wiley, 1998:271-89.

5 Weick KE, Quinn RE. Organisational change and development. Ann Rev Psychol 1999;50:361-86.

6 Weick KE. Quality improvement. A sensemaking perspective. In: Cole RE, Scott WR, eds. The quality movement and organisation theory. London: Sage, 2000.

7 McAdam D, McCarthy JD, Zald MN. Comparative perspectives on social movement. Political opportunities, mobilizing structures and cultural framings. Cambridge: Cambridge University Press, 1996.

8 Strang D, Jung I. Organisational change as an orchestrated social movement: determinants and implications of recruitment to a 'quality initiative'. Paper prepared for presentation at the Social Movement and Organisation Conference, Ann Arbor, May 2002.

9 Crossley N. Making sense of social movements. Buckingham: Open University Press, 2002.

10 Smelser N. Theory of collective behaviour. London: Routledge and Kegan Paul, 1962.

11 Mohrman SA, Gibson CB, Mohrman AM. Doing research that is useful to practice: a model and empirical exploration. Acad Manage J 2001;44:357-75.

12 Bate SP, Robert G. Where next for policy evaluation? Insights from researching NHS modernisation. Politics and Policy 2003;31:237-51.

13 Rynes SL, Bartunek JM, Daft RL. Across the great divide: knowledge creation and transfer between practitioners and academics. Acad Manage $J$ $2001 ; 44: 340-55$.

14 Campbell JL. Where do we stand? Common mechanisms in organisations and social movements research. Paper prepared for presentation at the Social Movement and Organisation Conference, Ann Arbor, May 2002.

15 Johnson B. Polarity management. Identifying and managing unsolvable problems. Amhurst, MA: HRD Press, 1996.

16 Palmer PJ. The courage to teach. Exploring the inner landscape of a teacher's life. San Francisco: Jossey Bass, 1997.

17 Gladwell M. The tipping point. How little things can make a big difference. London: Abacus, 2000. 
18 Bate SP, Robert G. Knowledge management and communities of practice in the private sector: lessons for modernising the NHS in England and Wales. Public Admin 2002;80:643-63.

19 Huy QN. Emotional capability, emotional intelligence and radical change. Acad Manage Rev 1999:24:325-45.

20 Kerr D, Bevan H, Gowland B, et al. Redesigning cancer care. BMJ 2002;324:164-6.

21 Ham C, Kipping R, McLeod H. Redesigning work processes in health care: lessons from the National Health Service. Milbank Quarterly 2003:81:415-39.

22 Bate SP. Strategies for cultural change. Oxford: Butterworth Heinemann, 1995.
23 Snow DA, BurkeRochford Jr E, Worden SK, et al. Frame alignment processes, micromobilization, and movement participation. Am Sociol Rev 1986;51:464-81.

24 McAdam D. Recruitment to high-risk activism: the case of Freedom Summer. Am J Sociol 1986:92:64-90.

25 Morris A. Charting futures for sociology: social organisation. Reflections on Social Movement Theory: criticisms and proposals. Contemporary Sociology. A Journal of Reviews 2000;29:445-54

26 Kling J. Narratives of possibility: social movements, collective stories and the dilemmas of practice. Paper presented at the New Social Movement and Community Organising Conference, University of Washington School of Social Work, November 1995. 